\title{
Eye injuries: a prospective survey of 5671 cases
}

\author{
CAROLINE J MACEWEN
}

From Glasgow Eye Infirmary

SUMMARY 5671 patients with injuries presenting to a busy eye casualty department were examined prospectively to determine the incidence, aetiology, and severity of the injury. Of these cases $69.9 \%$ occurred at work, $18.3 \%$ during leisure and domestic activities (excluding recognised sport), $2.3 \%$ during sport, and $1.9 \%$ were due to assaults; contact lens injury occurred in a further $2 \cdot 3 \%$, and the cause was unknown in $5.3 \%$. One hundred and two $(1.8 \%)$ patients required admission to hospital, and of their injuries $13.7 \%$ occurred at work, $22.6 \%$ during leisure and domestic activities, $42 \cdot 2 \%$ at sport, $18.6 \%$ during assault, and $2.9 \%$ from an unknown cause. Children under 10 years of age accounted for $4 \%$ of the total patients presenting, but for more than $18 \%$ of those admitted and $26 \%$ of ocular penetrations. $98.3 \%$ of all injuries involved periorbital or superficial ocular structures only. The remainder involved intraocular structures. The majority of serious injuries were contusional. There was only one case of intraocular foreign body. This indicates that, while most injuries still occur in the workplace, sport and leisure activities account for the majority of serious injuries. While most injuries do not threaten sight, they do so disproportionately in children.

Ocular trauma is a considerable cause of visual impairment' and utilisation of ophthalmic service resources. ' 2 However, there is little information on the cause, incidence, and severity of eye injuries. Prevention should form the basis of management, and in order to plan strategies for protection there is a need for collection of data. In the USA recent studies indicate that eye trauma, though largely preventable, still puts a considerable burden on eye departments. ${ }^{23}$ These reports, however, reflect different leisure activities, working habits, referral patterns, and protective legislation from those of the United Kingdom. Hitherto there has been little information on the aetiology of eye injuries in the UK. Most reports in this country concentrate only on injuries which necessitate hospital admission, ${ }^{46}$ occur during a particular activity, ${ }^{7-17}$ involve certain age groups, ${ }^{518}$ or involve a particular type of trauma. ${ }^{142}$ Casualty based studies have not linked the severity of injury to the cause and have tended to concentrate on demographic details and utilisation of services. ${ }^{21} 22$

The aim of this prospective study was to determine the incidence, aetiology, and severity of eye injuries presenting to a busy eye casualty department in the United Kingdom over a 12-month period.

Correspondence to C J Macewen, FRCS, Department of Ophthalmology, Ninewells Hospital and Medical School, Dundee.

\section{Patients and methods}

This study group comprised all patients presenting with ocular trauma to the combined Glasgow Eye Infirmary and Western Infirmary Casualty Department during 1 May 1987 to 30 April 1988. A proforma was drawn up so that the data could be recorded by the nursing staff, who initially see all patients in this department. The following details were recorded from each patient: age and sex, activity at the time of injury, type of injury, and presence or absence of protective eye wear (where appropriate). Corrective spectacles (without protective lenses) were not considered as a form of protection. If admission to hospital was required, the records were identified and further details of treatment and outcome were determined.

Activity at the time of injury was classified as follows: work, domestic and leisure (occurring in the home, garden, shopping, children playing, leisure activities excluding recognised sports), sport, assault, and contact lens wear. Those in whom the injury could have been due to a variety of activities or the history was not clear were designated as unknown.

In the final analysis only the most severe injury was recorded. For example, if a patient suffered 


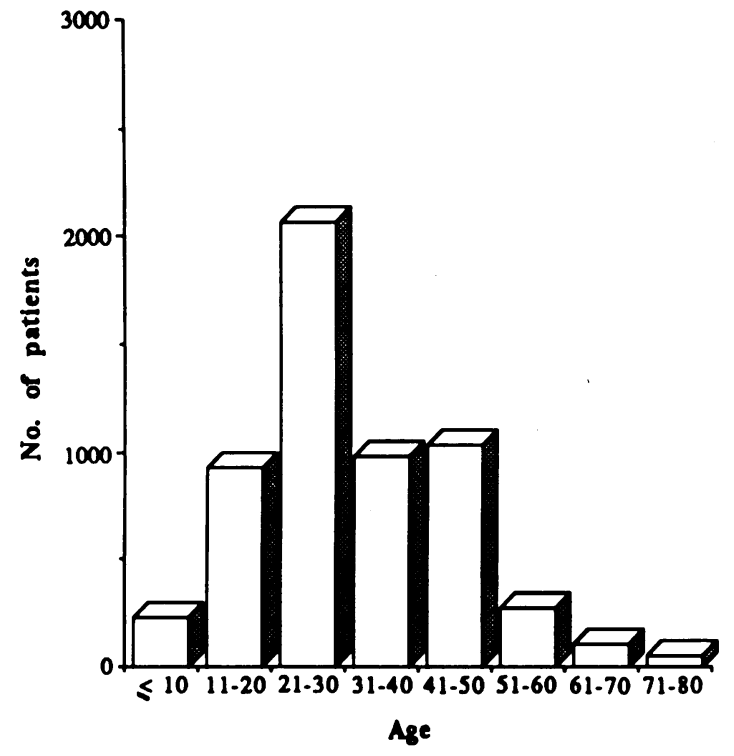

Fig. 1 Age distribution of patients presenting with ocular trauma.

hyphaema and retinal detachment, only the retinal detachment was recorded.

\section{Results}

There were 14955 new patients seen at this Casualty Department over the study period, of which 5671 presented with ocular trauma (38\%). Of these, 4940 $(87 \%)$ were male and $731(13 \%)$ female. The average age was 30.6 years (range 8 months to 77 years, Fig. 1). $5440(96 \%)$ were over 10 years of age and 231

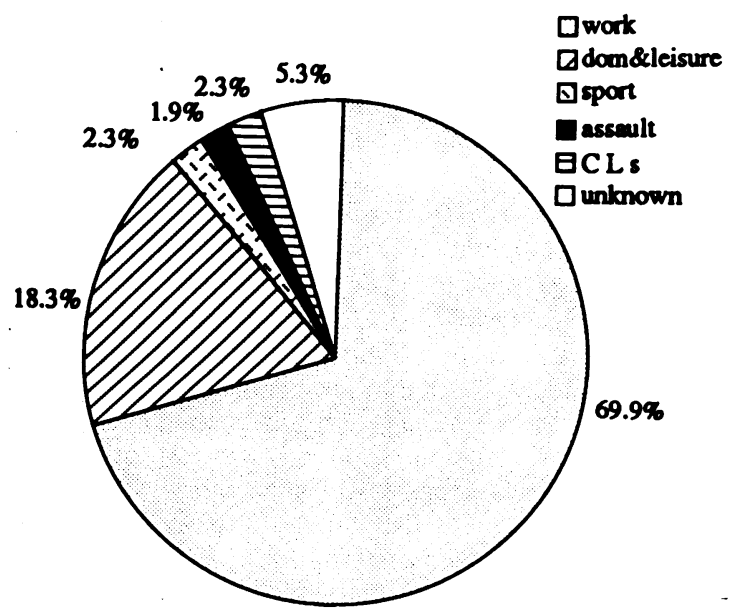

Fig. 2 Activity at time of injury in all patients presenting with ocular trauma. CLs=contact lenses.

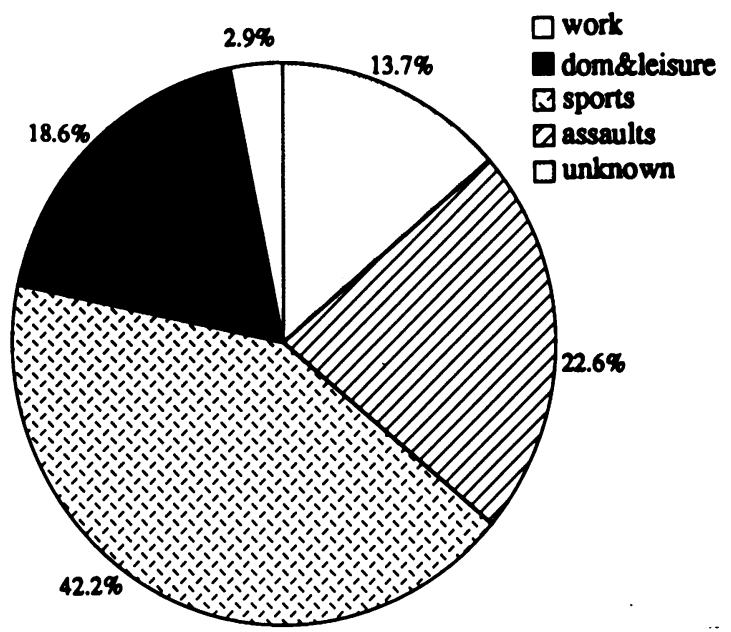

Fig. 3 Activity at time of injury in patients requiring admission to hospital with ocular trauma.

(4\%) were children up to age $10.5569(98 \cdot 2 \%)$ were treated as outpatients, of whom $1359(24 \%)$ required at least one follow-up appointment. The remaining $102(1.8 \%)$ were admitted to hospital; they represented $42 \%$ of the total 245 admitted cases from this department for all causes.

\section{ACTIVITY AT TIME OF INJURY}

$3963(69.9 \%)$ injuries occurred at work, $1034(18 \cdot 3 \%)$ during leisure and domestic activities (excluding sports), $131(2.3 \%)$ during sports, and $113(1.9 \%)$ were due to assaults. Contact lens induced injury occurred in a further $131(2 \cdot 3 \%)$. The cause of injury was unknown in $299(5 \cdot 3 \%)$ (Fig. 2).

\section{INJURIES NECESSITATING ADMISSION}

Of the 102 injuries which necessitated admission 14 $(13.7 \%)$ occurred at work, $23(22.6 \%)$ during leisure and domestic activities, $43(42 \cdot 2 \%)$ during sport, 19 $(18.6 \%)$ from assaults, and in $3(2.9 \%)$ the aetiology was unknown (Fig. 3). Of the injuries necessitating admission to hospital $19(18.6 \%)$ occurred in children under 10 years, though they accounted for only $4 \%$ of the total patients presenting. The proportion of injuries which required admission varied according to the activity at the time of injury: 14 of $3963(0.4 \%)$ at work, 23 of $1034(2.5 \%)$ during domestic work and leisure, 19 of $113(17 \%)$ from assaults, 43 of 131 $(33 \%)$ during sports, and 3 of $199(1 \%)$ in which the cause was unknown.

EXTENT OF INJURY

Injuries involving periocular tissues only numbered $156(2 \cdot 8 \%)$, of which 7 were facial or blow out fractures and 8 were lacerations which involved 
Table 1 Extent of injury occurring during different activities

\begin{tabular}{|c|c|c|c|c|c|c|c|}
\hline Injury & Work & $\begin{array}{l}\text { Domestic } \\
\& \text { leisure }\end{array}$ & Sport & Assault & Unknown & $C L s$ & Total \\
\hline Periocular & 36 & 47 & 26 & 47 & 0 & 0 & 156 \\
\hline EOFB & 2660 & 208 & 14 & 4 & 249 & 0 & 3155 \\
\hline Cor. Abr. & 625 & 580 & 31 & 30 & 41 & 98 & 1405 \\
\hline UV keratitis & 431 & 85 & () & () & 1 & () & 517 \\
\hline Conjunctival & 130 & 33 & 11 & 13 & 6 & 11 & 204 \\
\hline Chemical & 69 & 64 & () & () & 0 & 22 & 155 \\
\hline Uveitis & 4 & 2 & 12 & 6 & 0 & 0 & 24 \\
\hline Hyphaema & 3 & 5 & 21 & 1 & 1 & 0 & 31 \\
\hline Disloc lens & 0 & 0 & 1 & 1 & 0 & 0 & 2 \\
\hline Cataract & 1 & 0 & () & () & 0 & 0 & 1 \\
\hline Post. seg. & 2 & 1 & 14 & 4 & 0 & 0 & 21 \\
\hline Lac./rupture & 1 & 9 & 1 & 7 & 1 & 0 & 19 \\
\hline IOFB & 1 & 0 & () & () & 0 & () & 1 \\
\hline Total & 3963 & 1034 & 131 & 113 & 299 & 131 & 5671 \\
\hline
\end{tabular}

$\mathrm{EOFB}=$ extraocular foreign body. Cor abr. = corneal abrasion. Lac./rupture=laceration or rupture. IOFB=intraocular foreign body.

CLs=contact lenses.

either the cannaliculi or lid margin or caused loss of tissue. $2661(46.9 \%)$ were corneal foreign bodies, 474 $(8.4 \%)$ subtarsal foreign bodies, $1405(24 \cdot 8 \%)$ corneal abrasions, $517(9 \cdot 1 \%)$ ultraviolet keratitis, and $204(3 \cdot 6 \%)$ conjunctival lacerations or subconjunctival haemorrhages. $155(2 \cdot 7 \%)$ were chemical injuries, of which four were lime burns. There were 24 cases $(0.4 \%)$ of traumatic uveitis, $31(0.5 \%)$ hyphaemas, $1(0.02 \%)$ cataract, and $2(0.04 \%)$ lens dislocations. There were $21(0.4 \%)$ cases of contusional posterior segment damage, of which 4 were of vitreous haemorrhage, 5 choroidal tears, 6 retinal holes or detachments, and 6 significant retinal oedema. There were $18(0 \cdot 3 \%)$ ocular lacerations and 1 ruptured globe (contusional). There was only 1 $(0.02 \%)$ intraocular foreign body (Table 1$)$.

\section{INJURIES AT WORK}

Injuries at work numbered $3963 ; 3918(98 \cdot 8 \%)$ of the patients were male and $45(1.2 \%)$ were female. The type of work performed was grinding/buffing in 1841

Table 2 Occupation at time of injury

\begin{tabular}{|c|c|c|c|c|}
\hline \multirow[t]{2}{*}{ Type of work } & \multicolumn{2}{|c|}{ Protection not worn } & \multirow[b]{2}{*}{$\begin{array}{l}\text { Protection } \\
\text { worn }\end{array}$} & \multirow[b]{2}{*}{ Total } \\
\hline & Required & $\begin{array}{l}\text { Not } \\
\text { required }\end{array}$ & & \\
\hline Grinding/buffing & 1492 & 44 & 305 & 1841 \\
\hline Weld & 683 & 47 & 172 & 902 \\
\hline Under car & 408 & 155 & 74 & 717 \\
\hline Drilling/hammering & 192 & 88 & 46 & 326 \\
\hline Loading/stacking & 16 & 52 & 4 & 72 \\
\hline Office & 0 & 21 & 0 & 21 \\
\hline Others & 29 & 45 & 10 & 84 \\
\hline Total & 2900 & 452 & 611 & 3693 \\
\hline
\end{tabular}

(46.5\%) cases, welding in $902(22 \cdot 8 \%)$, working in a dusty atmosphere or under a car in $717(18 \cdot 1 \%)$, drilling or hammering in $326(8.2 \%)$, loading or stacking goods in $72(1.8 \%)$, office work in 21 $(0 \cdot 1 \%)$, and miscellaneous in $83(2 \cdot 1 \%)$ (Table 2$)$. The majority of injuries were superficial, corneal foreign bodies accounting for $2192(55 \cdot 3 \%)$, subtarsal foreign bodies for $468(11.8 \%)$, corneal abrasion for $625(15 \cdot 8 \%)$, bruising for $36(0.9 \%)$, flash burn for $431(10.9 \%)$, conjunctival injury for $130(3 \cdot 3 \%)$, chemical burns for $69(1 \cdot 7 \%) .12(0 \cdot 3 \%)$ involved intraocular structures: uveitis 4 , hyphaema 3 , cataract 1 , posterior segment damage 2 , globe rupture 1, and intraocular foreign body 1 (Table 1 ).

No form of eye protection was worn by 3352 $(84.6 \%)$ at the time of injury, though for the majority this was available; $452(11.4 \%)$ indicated that they had not felt protection was required. $611(15.4 \%)$ were wearing some form of eye protection at the time of injury (Table 2). No serious injury occurred at work in those who were wearing eye protection.

\section{LEISURE AND DOMESTIC}

1034 injuries occurred during leisure and domestic activities (excluding recognised sports). Of these injuries $450(43.5 \%)$ occurred in adult men, 383 $(37 \%)$ in adult women, and $201(19.5 \%)$ in children up to 10 years. Most of these injuries were periorbital, but a significant number, especially in the younger patients caused serious sight threatening injury. Of the 23 patients admitted $17(78 \%)$ were aged 10 or under. They had all either fallen on to or been struck by a potentially penetrating object. Seven were admitted for examination under anaesthetic, when no serious damage was found other than lid or conjunctival laceration. However, there were 5 
Table 3 Mechanism of injury during domestic and leisure activities

\begin{tabular}{lc}
\hline Mechanism of injury & Number \\
\hline Struck by or fell into large object & 563 \\
Small foreign body & 302 \\
UV light & 85 \\
Toxic material & 84 \\
Total & 1034 \\
\hline
\end{tabular}

ocular penetrations, 4 hyphaemas and 1 choroidal tear in this age group. Four of the 5 admitted adults had a lacerated or ruptured globe.

Of the superficial injuries $232(22 \cdot 4 \%)$ were caused by a child's finger scratching the eye; $84(8.1 \%)$ patients presented with ultraviolet keratitis caused by sunray lamps, none of whom were wearing protective goggles (Table 3 ). There were 25 injuries from road traffic accidents, all of which were superficial. There were no firework injuries.

\section{SPORT}

Injuries during sporting activities numbered 131 (Table 4$)$. Of these patients $43(33 \%)$ ) were admitted to hospital. There were $112(85.5 \%)$ adult males and $13(9.9 \%)$ adult females, and $6(4.6 \%)$ were children up to 10 . The sport involved was football in 55 cases $(42 \%)$, squash in $13(9.9 \%)$, badminton in $9(6.9 \%)$, rugby in $7(5.3 \%)$, golf in $6(4.6 \%)$, cycling in 5 $(3 \cdot 8 \%)$, swimming in $5(3 \cdot 8 \%)$, and other sports 31
$(24 \cdot 7 \%)$. Of these injuries $82(62 \cdot 6 \%)$ were superficial, involving the external eye or periorbital tissues, which included 2 severe lid lacerations and 4 blowout fractures, and $49(37.4 \%)$ involved intraocular structures (Table 4). No patient was wearing any form of eye protection when injured during sport. Of the 43 cases admitted $22(51 \cdot 1 \%)$ occurred during football, $7(16.3 \%)$ during badminton, $4(9.3 \%)$ during squash, $2(4 \cdot 7 \%)$ during shinty, $2(4 \cdot 7 \%)$ while fishing, and $6(13.9 \%)$ in other sport. Sports played with a ball predominated, and the ball was responsible for injury in the majority of cases admitted. There were no boxing injuries.

\section{CONTACT LENS INJURY}

Patients with contact lens injuries numbered 131. None required admission, as all the injuries were superficial due to poorly fitting contact lenses, overwear of lenses, or incorrect use of solutions. Allergy to solutions was not considered a form of trauma.

\section{ASSAULTS}

There were 113 injuries caused by assault; $19(16 \cdot 8 \%)$ of these patients were admitted to hospital: 91 $(80.5 \%)$ were male, $21(18.6 \%)$ female, and $1(0.9 \%)$ a child under 10 . The exact nature of the assault was not always clear. Most of the injuries were periorbital; they included 2 blow-out fractures, 1 fractured malar complex, and 3 facial/lid lacerations. There were 7 cases of globe penetration, 1 of dislocated lens, and 4 of blunt trauma causing posterior segment damage.

Table 4 Extent of injury during sporting activities

\begin{tabular}{|c|c|c|c|c|c|c|c|c|c|}
\hline Sport & Periororbital $F$ & $F B$ & Corneal & Conj & Uveitis & Hyphaema & Post. Seg & Rupture & Total \\
\hline Football & 12 & 2 & 12 & 2 & 6 & 10 & 11 & () & 55 \\
\hline Squash & 2 & 0 & 4 & () & 3 & 3 & 1 & () & 13 \\
\hline Badminton & 0 & 0 & 1 & 0 & 1 & 6 & 1 & 0 & 9 \\
\hline Rugby & 5 & 0 & 2 & 0 & () & 0 & 0 & () & 7 \\
\hline Golf & 1 & 2 & 3 & 0 & 0 & 0 & 0 & () & 6 \\
\hline Cycling & 0 & 2 & 2 & 1 & 0 & 0 & 0 & () & 5 \\
\hline Swimming & 0 & 0 & 3 & 2 & 0 & 0 & () & 0 & 5 \\
\hline Other & 8 & 1 & 11 & 3 & 3 & 2 & 2 & 1 & 31 \\
\hline Total & 28 & 7 & 38 & 8 & 13 & 21 & 15 & 1 & 131 \\
\hline
\end{tabular}

Table 5 Final visual acuities of admitted patients

\begin{tabular}{|c|c|c|c|c|c|c|}
\hline Acuity & Work & $\begin{array}{l}\text { Domestic and } \\
\text { leisure }\end{array}$ & Sport & Assault & Unknown & Total \\
\hline $6 / 5-6 / 12$ & 12 & 18 & 37 & 8 & 2 & 77 \\
\hline $6 / 18-6 / 60$ & 0 & 1 & 1 & 2 & 0 & 4 \\
\hline CF-HM & 2 & 4 & 3 & 3 & 0 & 12 \\
\hline PL-NPL & 0 & 0 & 0 & 2 & 1 & 3 \\
\hline Unknown & 0 & 0 & 2 & 4 & () & 6 \\
\hline Total & 14 & 23 & 43 & 19 & 3 & 102 \\
\hline
\end{tabular}


AETIOLOGY UNKNOWN

The cause of injury was not certain in 299 patients. These injuries were largely superficial corneal abrasions or foreign bodies, and they could have occurred during a variety of activities. Three (1\%) were admitted to hospital, a 2-year-old child with a delayed presentation of ruptured globe and 2 mentally retarded adults with hyphaema.

\section{ADMITTED CASES}

Of the 102 admitted patients $37(36 \cdot 3 \%)$ underwent surgical intervention. Eight had examination under anaesthetic and simply required suture of a lid or conjunctival laceration. Nineteen had corneoscleral lacerations closed, 6 had retinal detachment surgery, and 2 lensectomy-vitrectomy procedures. One intraocular foreign body was removed in combination with lensectomy-vitrectomy and corneal graft. The malar complex was elevated in one patient. Of the hyphaemas 2 bled again (no surgical intervention), 4 had a prolonged increase in intraocular pressure (1 trabeculectomy), 4 had significant residual mydriasis, and 7 had angle recession. There were no enucleations. The final visual acuities of admitted patients were good (Table 5). The length of admission varied from 1 to 44 days (mode 4 days).

\section{Discussion}

Despite the fact that eye trauma accounts for 1 in 20 cases seen by ophthalmologists, ${ }^{1}$ many consider it has not received the attention it deserves. ${ }^{23}$ In the present study $38 \%$ of all new patients seen at this casualty department presented because of injury. This is in keeping with previous studies indicating an incidence of between $45-52 \% .^{2122}$ It therefore takes up a considerable proportion of casualty time. $90 \%$ of eye injuries are said to be preventable, and implementation of protective legislation has been effective in certain circumstances. In 1923 (prior to the institution of British Standards for industrial eye protection), $71 \%$ of cases admitted to hospital with eye trauma were due to occupational accidents, ${ }^{4}$ but this had fallen to $15 \%$ by $1980 .{ }^{6}$ Road traffic accidents were a major source of penetrating eye injury prior to the introduction of the seat belt law in $1983^{161924}$ but now are rarely responsible for severe eye injuries. ${ }^{6171924}$ The introduction of face mask protectors in ice hockey has reduced an estimated 70000 eye injuries annually in North America. ${ }^{25}$ In the United States the National Eye Trauma System has been set up to examine the aetiology and thereby allow planning of severe eye trauma. No such data collection system exists in Great Britain, though collection of information on a nationwide scale has been attempted in certain areas. ${ }^{27}$
Most reported eye injuries are superficial, but their cost in terms of health budgets and absence from work have been estimated to be enormous. ${ }^{2}$ In addition, the long term outcome, especially in cases of blunt trauma, has not yet been fully established.

\section{OCCUPATIONAL}

The present study has shown that the majority of injuries still occur in the workplace, usually while the patient was carrying out light industrial tasks. Most of these injuries were superficial, but they accounted for a significant amount of time taken off work to attend the casualty department and for follow-up. At the time of injury most of the patients were not wearing any eye protection, though this was usually available. Reasons given for not wearing it were: discomfort, inability to see the task being performed, forgot, or did not feel that it was really necessary. Interestingly, many people working under cars or in dusty atmospheres thought that protection was unnecessary, and some workers remain unaware of the dangers of hammering without eye protection. $15.4 \%$ were wearing some form of eye protection, but this had failed to work adequately. The lack of efficacy of eye protection was in the main attributed to: foreign material entering the side of protective glasses, foreign material falling off protective glasses into the eyes, or ill fitting devices. Almost one-fifth of welders and grinders suffered injury despite wearing protection.

A small minority of injuries $(0.4 \%$ of all work injuries) were serious enough to require the patient's admission to hospital. There was only one case of intraocular foreign body and one of globe penetration occurring at work, a proportion significantly lower than has been reported in the United States $^{2}$ and earlier in Britain. ${ }^{4-6}$ No serious injury requiring admission occurred when eye protection was in use, suggesting that existing protective eye wear is effective against severe injury. It is important to encourage the continued use of occupational eye protectors and constantly improve the devices available.

\section{DOMESTIC AND LEISURE}

This was a common source of ocular trauma, especialy in women and children (accounting for $61 \%$ of all women's injuries and $87 \%$ of children's). Most injuries were superficial. The commonest causes were large objects scratching the front of the eye, especially children's fingers, domestic appliances, and toys.

Domestic cleaning fluids and cosmetics caused the majority of chemical injuries. Males commonly suffered superficial injuries during do-it-yourself tasks, car repairs, and gardening. 
One disturbing feature of the injuries in this group was the number of ocular penetrations - representing almost $50 \%$ of those in the total series. Most of these injuries occurred in children up to 10 . There is evidence that the incidence of penetrating injuries in children is declining, ${ }^{28}$ but in this study $26 \%$ of these injuries occurred in children. Other studies have shown that children are disproportionately liable to severe eye injury. ${ }^{24}$

There should be increased awareness that the home is an area in which serious eye injuries can occur, commonly in the young. Men often wear protective devices at work but fail to do so at home when carrying out similar DIY tasks.

Road traffic accidents were responsible for only a small number of superficial injuries. Ultraviolet keratitis due to the use of sunray lamps without eye filters may be an increasing problem.

\section{SPORTS}

One of the most interesting findings of this study was that, while sports accounted for only $2 \cdot 3 \%$ of the total eye injuries, they were responsible for $42 \%$ of the cases admitted to hospital. This indicates that sport is now a major source of serious eye injury. $68 \%$ of all hyphaemas and $67 \%$ of posterior segment injuries occurred while playing sport, reflecting the blunt nature of the trauma. Recently it has been shown in the USA that although sport was responsible for $3.4 \%$ of eye injuries it was responsible for $60 \%$ of hyphaemas and $10 \%$ of ruptured globes in the adult population. ${ }^{2}$ Studies in Britain show a similar disturbing pattern of serious eye injury associated with sport, ${ }^{8912212930}$ despite the different types of sport played on opposite sides of the Atlantic (baseball and soft ball being the commonest causes of eye injuries in the United States). Soccer is the commonest cause in various studies in the UK ${ }^{891+}$ but this has largely been ignored, with most emphasis on the racquet sports played with a small ball, especially squash. ${ }^{1122930}$ The size of the ball is thought to be of utmost importance and anything greater than 4 inches $(10 \mathrm{~cm})$ in diameter should be unable to enter the bony aperture and therefore distribute its force to the periorbital tissue. This has not been borne out in fact. The football is responsible for most severe soccer injuries, and the momentum of the heavy ball causes posterior segment damage more commonly in footballers than any other sport. Scottish Sport Council figures indicate that football is four times more commonly played than squash (adult) on both a supervised and unsupervised basis (Best JP, personal communication), suggesting that injuries are equally common in both sports pro rata but the football injuries are more severe. This may reflect the use of goggles by squash players.
Development of eye protection for sporting activities which meet adequate standards with appropriate optical and visual field requirements is essential. This is not a problem with racquet sports, but the present rules of football allow no place for such protection. We must encourage players to be aware of the dangers of sport and to wear protection where appropriate. Unfortunately there is at present no British Standard, and eye protectors are not readily available because of poor demand..$^{14}$

\section{ASSAULTS}

Injuries due to assaults were distributed over the whole range of injury, from minimal contusions to extensive disruption of the globe. This was the commonest cause of ocular penetration in adults and was responsible for the most devastating visual loss. Assaults are commonly sited as a common cause of serious eye injury, ${ }^{2-4}$ but the circumstances and cause are often difficult to determine.

\section{IMPLICATIONS AND CONCLUSIONS}

The main findings of this study are that ocular trauma is a common cause of presentation to the eye casualty department. While occupational accidents still account for the majority of injuries, leisure and sport are now causing a significant number of injuries. Moreover the latter cause most injuries which require hospital admission. A disproportionate amount of serious eye injury occurs in children. The majority of serious eye injuries were contusional, with fewer perforations and intraocular foreign bodies.

It appears that there is still scope for improvement of the design and use of eye protection, especially in sport. Large surveys, preferably on a national basis, may provide sufficient data to increase public awareness and so expedite the appropriate measures.

I would like to thank all the nursing staff in the Glasgow Eye Infirmary and Western Infirmary Eye Casualty Department for their co-operation and assistance and Mrs Lynda Rose for typing the manuscript.

\section{References}

1 National Society to Prevent Blindness: Fact Sheet. New York: National Society to Prevent Blindness, 1980.

2 Schein OD, Hibberd PL, Shingleton BJ, et al. Spectrum and burden of ocular injury. Ophthalmology 1986: 95: 300-5.

3 Karlson TA, Klein BEK. The incidence of acute hospital treated eye injuries. Arch Ophthalmol 1986; 104: 2473-6.

4 Garrow A. A statistical enquiry into a thousand cases of eye injury. Br J Ophthalmol 1923; 7: 65-80.

5 Lambah P. Adult eye injuries at Wolverhampton. Trans Ophthalmol Soc UK 1968; 88: 661-73.

6 Canavan YM, O'Flaherty MJ, Archer DB, Elwood JH. A 10year survey of eye injuries in Northern Ireland. 1967-1976. Br J Ophthalmol 1980; 64: 618-25.

7 Johnson SS. The changing pattern of injury. Trans Ophthalmol Soc UK 1975; 95: 307-10. 
8 MacEwen CJ. Sport associated eye injury: a casualty department survey. Br J Ophthalmol 1987; 71: 701-5.

9 Jones NP. Eye injuries in sport: an increasing problem. $\mathrm{Br} J$ Sports Med 1987; 21: 168-70.

10 Kelly S, Nolan J. Eye injuries in organised sport in a rural area. Br J Ophthalmol 1983; 67: 837-9.

11 Kennerley Bankes JL. Squash racquets: a survey of eye injuries in England. Br Med J 1985; 291: 1539.

12 Chandran S. Ocular hazards of playing badminton. $\mathrm{Br} J$ Ophthalmol 1974; 58: 757-60.

13 Elliott AJ, Jones D. Major ocular trauma: a disturbing trend in field hockey injuries. $\mathrm{Br}$ Med J 1984; 289: 21-2.

14 Gregory PTS. Sussex Eye Hospital sports injuries. $\mathrm{Br} J$ Ophthalmol 1986; 70: 748-50.

15 Cole MD, Smerdon D. Perforating injuries caused by darts. $\mathrm{Br} \mathrm{J}$ Ophthalmol 1988: 72: 511-4.

16 Mackay GN. Incidence of trauma to the eyes in car occupants. Trans Ophthalmol Soc UK 1975; 95: 311-4.

17 Vernon SA. Yorston DB. Incidence of ocular injuries from road traffic accidents after introduction of seat belt legislation. $J$ Soc Med 1984: 77: 198-200.

18 Lambah P. Some common causes of eye injury in the young. Lancet 1962: ii: 1351-3.

19 Wykes WN. A 10-year survey of penetrating eye injuries in Gwent, 1976-85. Br J Ophthalmol 1980; 72: 607-11.
20 Eagling EM. Perforating injuries of the eye. Br J Ophthalmol 1980; 64: 618-25.

21 Vernon SA. Analysis of all new cases seen in a busy regional centre of an ophthalmic casualty department during a 24 week period. J R Soc Med 1983; 76: 279-82.

22 Chiapella AP, Rosenthal AR. One year in an eye casualty clinic. Br J Ophthalmol 1985; 69: 865-70.

23 Parver LM. Eye trauma. The neglected disorder. (Editorial.) Arch Ophthalmol 1986; 104: 1452-3.

24 Hall NF, Denning AN, Elkington AR, Cooper PJ. The eye and the seat belt in Wessex. Br J Ophthalmol 1985; 69: 317-9.

25 Pashby PJ, Pashby RC, Chisholm LDJ, et al. Eye injuries in canadian hockey. Can Med Assoc J 1975; 113: 663-6.

26 Pashby CM. Eye injuries in Canadian amateur hockey. Can J Ophthalmol 1985: 20: 2-4.

27 Elkington AR. Boxing and the eye. Trans Ophthalmol Soc UK 1985; 104: 898-902.

28 Nhranen M, Raviaoi I. Eye injuries in children. Br J Ophthalmol 1981: 65: 436-8.

29 Davey JB. Eye injuries in the game of squash. Optometry Today 1986: $236-40$.

30 Ingram DV, Lewkonia I. Ocular hazards of playing squash racquets. Br J Ophthalmol 1973: 57: 434-8.

Accepted for publication 11 May 1989. 